\title{
Methodological recommendations for assessing scleractinian and octocoral recruitment to settlement tiles
}

\author{
Leah M Harper ${ }^{\text {Corresp., } 1,2}{ }^{\text {, Lindsay K Huebner }}{ }^{3}$, Elijah D O'Cain ${ }^{4,5}$, Rob Ruzicka ${ }^{3}$, Daniel F Gleason ${ }^{4}$, Nicole D \\ Fogarty ${ }^{1,6}$ \\ 1 Halmos College of Natural Sciences and Oceanography, Nova Southeastern University, Dania Beach, FL, United States \\ 2 Tennenbaum Marine Observatories Network, MarineGEO, Smithsonian Environmental Research Center, Edgewater, MD, United States \\ 3 Fish and Wildlife Research Institute, Florida Fish and Wildlife Conservation Commission, Saint Petersburg, FL, United States \\ 4 James H. Oliver, Jr., Institute for Coastal Plain Science, Georgia Southern University, Statesboro, GA, United States \\ 5 Coastal Resources Division, Georgia Department of Natural Resources, Brunswick, GA, United States \\ 6 Department of Biology and Marine Biology, Center for Marine Science, University of North Carolina Wilmington, Wilmington, NC, United States \\ Corresponding Author: Leah M Harper \\ Email address: harperl@si.edu
}

Quantifying recruitment of corals is important for evaluating their capacity to recover after disturbances through natural processes, yet measuring recruitment rates in situ is challenging due to the minute size of the study organism and the complexity of benthic communities. Settlement tiles are widely used in studies of coral recruitment because they can be viewed under a microscope to enhance accuracy, but methodological choices such as the rugosity of tiles used and when and how to scan tiles for recruits post-collection may cause inconsistencies in measured recruitment rates. We deployed 2880 tiles with matching rugosity on top and bottom surfaces to 30 sites along the Florida Reef Tract for year-long saturations during a three year study. We scanned the top and bottom surfaces of the same tiles for scleractinian recruits before (live scans) and after treating tiles with sodium hypochlorite (corallite scans). Recruit counts were higher in corallite than live scans, indicating that scleractinian recruitment rates should not be directly compared between studies using live scans and those scanning tiles, which have been processed to remove fouling material. Recruit counts also were higher on tile tops in general, but the proportion of settlement to the top and bottom surfaces varied significantly by scleractinian family. Thus, biases may be introduced in recruitment datasets by differences in tile rugosity or by only scanning a subset of tile surfaces. Finally, we quantified octocoral recruitment during live scans and found they preferentially settled to tile tops. We recommend that recruitment tile studies include corallite scans for scleractinian skeletons, deploy tiles with matching rugosity on top and bottom surfaces, and scan all tile surfaces. 
1 Methodological recommendations for assessing scleractinian and octocoral recruitment to

2 settlement tiles

3 Leah M. Harper ${ }^{1,2^{*}}$, Lindsay K. Huebner ${ }^{3}$, Elijah D. O’Cain ${ }^{4,5}$, Rob Ruzicka ${ }^{3}$, Daniel F.

4 Gleason $^{4}$, Nicole D. Fogarty ${ }^{1,6}$

5 1'Nova Southeastern University, Halmos College of Natural Sciences and Oceanography, $8000 \mathrm{~N}$

6 Ocean Drive, Dania Beach, FL 33004

7 2Present address: Tennenbaum Marine Observatories Network, MarineGEO, Smithsonian

8 Environmental Research Center, Edgewater, Maryland 21037

$9{ }^{3}$ Fish and Wildlife Research Institute, Florida Fish and Wildlife Conservation Commission, 100

10 8th Ave SE, Saint Petersburg, FL 33701

$11{ }^{4}$ James H. Oliver, Jr., Institute for Coastal Plain Science, P.O. Box 8042, Georgia Southern

12 University, Statesboro, GA 30460-8042

13 5Present address: Georgia Department of Natural Resources, Coastal Resources Division, 1

14 Conservation Way, Brunswick, GA 31520-8687

15 6Present address: Department of Biology and Marine Biology, Center for Marine Science,

16 University of North Carolina Wilmington, 5600 Marvin K. Moss Lane, Wilmington, NC 28412

$17 *$ Contact email: harperl@si.edu

18 Keywords: recruitment, settlement tile, rugosity, Scleractinia, Octocorallia, Florida Reef Tract

19

20

21

22

23 


\section{Abstract}

25 Quantifying recruitment of corals is important for evaluating their capacity to recover after

26 disturbances through natural processes, yet measuring recruitment rates in situ is challenging due

27 to the minute size of the study organism and the complexity of benthic communities. Settlement

28 tiles are widely used in studies of coral recruitment because they can be viewed under a

29 microscope to enhance accuracy, but methodological choices such as the rugosity of tiles used

30 and when and how to scan tiles for recruits post-collection may cause inconsistencies in

31 measured recruitment rates. We deployed 2880 tiles with matching rugosity on top and bottom

32 surfaces to 30 sites along the Florida Reef Tract for year-long saturations during a three year

33 study. We scanned the top and bottom surfaces of the same tiles for scleractinian recruits before

34 (live scans) and after treating tiles with sodium hypochlorite (corallite scans). Recruit counts

35 were higher in corallite than live scans, indicating that scleractinian recruitment rates should not

36 be directly compared between studies using live scans and those scanning tiles, which have been

37 processed to remove fouling material. Recruit counts also were higher on tile tops in general, but

38 the proportion of settlement to the top and bottom surfaces varied significantly by scleractinian

39 family. Thus, biases may be introduced in recruitment datasets by differences in tile rugosity or

40 by only scanning a subset of tile surfaces. Finally, we quantified octocoral recruitment during

41 live scans and found they preferentially settled to tile tops. We recommend that recruitment tile

42 studies include corallite scans for scleractinian skeletons, deploy tiles with matching rugosity on

43 top and bottom surfaces, and scan all tile surfaces.

\section{Introduction}

45 Settlement tiles are often used to evaluate variation in coral recruitment through time and space

46 (Rogers et al., 1984; Edmunds, 2017; Davidson et al., 2019). Tiles can be removed from study 
47 sites and examined under a microscope, facilitating identification of small recruits and allowing

48 an assessment of recruitment during a defined time period. However, various methodological

49 options exist for conducting settlement tile studies which can influence the resultant recruitment

50 rates, making interstudy comparisons problematic and ecological interpretations inconsistent

51 (Table S1).

52 One such methodological decision that can affect quantified recruitment is the technique

53 used to scan tiles for settled corals. Tiles can be scanned for living recruits shortly after retrieval,

54 typical for studies estimating recruit survivorship (e.g., Arnold, Steneck, \& Mumby, 2010) or for

55 sampling recruit tissue for molecular identification (O'Cain et al., 2019; Guerrini et al., 2020).

56 Alternatively, tiles can be soaked in sodium hypochlorite to reveal corallite morphology (Harriott

57 \& Fisk, 1987), which can be used to more accurately identify recruits than is possible during live

58 visual scans, and to remove encrusting organisms that potentially obscured recruits which

59 experienced post-settlement mortality.

60 Whether to scan all tile surfaces (top, bottom, and sides) or only a subset represents

61 another methodological choice. For most studies that have compared tile surfaces, $>90 \%$ of

62 recruits were found on the bottom surface (Green \& Edmunds, 2011; Edmunds, Nozawa, \&

63 Villanueva, 2014; Humanes \& Bastidas, 2015). Consequently, some studies exclude the top

64 surface from analysis (Chong-Seng, Graham, \& Pratchett, 2014; Burt \& Bauman, 2020; Gouezo

65 et al., 2020). However, commonly there are differences in rugosity on tile surfaces used in

66 recruitment studies (Green \& Edmunds, 2011; Edmunds, 2017; Lal et al., 2018), with tops being

67 smooth and bottoms bearing textures which provide microhabitat refugia for recruits. Tile

68 rugosity may mimic heterogenous natural substratum and enhance rates of scleractinian

69 recruitment and survivorship on tiles (Nozawa, 2008; Edmunds, Nozawa, \& Villanueva, 2014; 
70 Randall et al., 2021); if the top surface of the tile is also textured, the proportion of settlement

71 there can be increased (Edmunds, Nozawa, \& Villanueva, 2014). Thus, rugosity differences

72 between tile top and bottom surfaces may confound recruitment data, as can scanning only a

73 subset of tile surfaces.

74 Most coral reef settlement tile literature focuses on scleractinian recruitment. However,

75 as scleractinians have declined throughout the Caribbean, octocoral densities have remained

76 stable or increased (Ruzicka et al., 2013; Edmunds \& Lasker, 2016; Lasker et al., 2020).

77 Octocoral recruitment is typically quantified in situ (Lasker, 2013; Lasker \& Porto-Hannes,

78 2021) and rarely on tiles, potentially leaving gaps in understanding the spatial and temporal

79 variation in octocoral recruitment.

80 During a study initially designed to investigate the spatial and temporal variation in

81 scleractinian and octocoral recruitment on 2,778 settlement tiles deployed throughout the Florida

82 Reef Tract (Harper et al., in prep.), we observed methodological inconsistencies in the coral

83 recruitment literature (Table S1). We therefore designed our study to also collect companion data

84 on our methodological choices, in an effort to critically examine the potential implications of

85 these choices, and of those made in other studies, on the ecological results. Specifically, we

86 present here an assessment of recruitment tile methods in which we 1) compare scleractinian

87 recruitment rates quantified through live and corallite scans on the same tiles, 2) compare

88 scleractinian recruitment overall and by taxonomic family to the tops and bottoms of tile surfaces

89 with matching rugosity, and 3) quantify live octocoral recruits on the top and bottom surfaces of

90 the same tiles. We conclude with recommendations for future coral recruitment studies on tile

91 rugosity, and when and how to scan tiles for scleractinian and octocoral recruits.

\section{Methods}


93 Tiles were deployed at 30 sites along the Florida Reef Tract, from Broward County in the north

94 to Key West in the south, with depths ranging from 1.5 to $18 \mathrm{~m}$ (Fig. 1, Table S2), in accordance

95 with the following authorizations: Florida Keys National Marine Sanctuary Permit FKNMS-

96 2013-058-A1, Department of the Army Permit SAJ-2014-01396, and Broward County

97 Environmental Resource License DF14-1048. Tiles were unglazed terracotta $(15 \times 15 \times 1 \mathrm{~cm})$,

98 consistent with many previous studies of coral recruitment (Mundy, 2000; Arnold \& Steneck,

99 2011; Green \& Edmunds, 2011; Edmunds, Nozawa, \& Villanueva, 2014; van Woesik, Scott, \&

100 Aronson, 2014; Humanes \& Bastidas, 2015). Because each tile was smooth on one surface and

101 grooved on the other, tiles were deployed in back-to-back pairs, with grooved surfaces facing

102 outward, to provide consistent rugosity on the top and bottom of each tile pair (Fig. 2A-B).

103 At each of 30 sites (Fig. 1, Table S2), we haphazardly deployed 32 tile pairs by attaching

104 them to the substratum. Tile pairs were arranged along four permanent transects $\sim 22 \mathrm{~m}$ in length

105 at each site, with eight tile pairs per transect. The distance between nearest neighboring tiles was

$106 \cong 1-10 \mathrm{~m}$. Using a pneumatic drill attached to a SCUBA cylinder, we drilled holes in the

107 substratum with a carbide drill bit $(1.25-1.59 \mathrm{~cm}$ diameter), into which we placed $1.25 \mathrm{~cm}$

108 diameter ribbed plastic drywall anchors. Tile pairs were secured, generally parallel to the

109 substratum, using a stainless steel lag screw $(0.64 \mathrm{~cm}$ diameter, $5-13 \mathrm{~cm}$ length, depending on

110 substratum rugosity) inserted through pre-drilled center holes in the paired tiles and screwed into

111 the drywall anchor (Fig. 2A-B). Tile deployments occurred from February to April in 2015,

112 2016, and 2017 (Table S2), allowing a minimum of four weeks for settlement tiles to condition

113 before expected Porites astreoides planulation (Edmunds, Gates, \& Gleason, 2001). Tiles were

114 retrieved approximately 12 months after deployment (range 11.5-13.5 months) in each of 2016,

115 2017, and 2018 (Table S2). Tiles were removed from the substratum and transported on racks 
116 made from two layers of egg crate material with bolts to hold the tiles in place and nuts to space

117 the tiles from the racks, preventing possible damage to recruits (Fig. 2C).

118 The grooved top and bottom of tile pairs were submerged in trays of seawater while

119 examined under a dissecting microscope for living scleractinian and octocoral recruits (Fig.

120 2D,F). Subsequently, tiles were submerged in 10\% sodium hypochlorite solution for 24-48h to

121 remove live tissue, then dried for scleractinian corallite scans (octocorals do not leave skeletal

122 material behind). During corallite scans, the grooved top and bottom surfaces were examined a

123 second time to locate scleractinian recruit skeletons (Fig. 2E,G). We additionally scanned the tile

124 sides (edges) for corallites, which was not possible during live scans with the tiles submerged in

125 trays. To determine whether taxonomic groups of scleractinians settled in different proportions

126 across tile surfaces, corallites were identified to the family level using diagnostic characteristics

127 such as shape, calice diameter at budding stage, columella development, and septal arrangement

128 and dentition (Smith, 1971; Budd et al., 2001; Budd \& Stolarski, 2011; Humblet, Hongo, \&

129 Sugihara, 2015). Corallites that were damaged, underdeveloped, or did not meet diagnostic

130 criteria were classified as unidentified. Diagnostic characteristics were supported with molecular

131 evidence using a single-step nested multiplex PCR assay designed to identify Caribbean

132 scleractinian recruits, developed from a subset of recruits sampled during live scans (O'Cain et

133 al., 2019). Further, we conducted blind inter-observer comparisons of corallite identifications to

134 ensure standardization.

135 To determine whether scan method (live vs. corallite) influenced recruit count, we fit a

136 negative binomial generalized linear model with a log link (GLM) in R v.4.0.3 (R Core Team,

137 2020) using the package MASS (Venables \& Ripley, 2002). We modeled the effects of the fixed

138 factors of site, year, location on tile, and scan method (allowing for an interaction between 
139 location and scan method) on the response variable recruit count. Model assumptions were

140 assessed visually. We evaluated the significance of fixed effects with Type II analysis of

141 deviance using the 'car' package (Fox \& Weisberg, 2019). In addition, we modeled the effects

142 of scan method, location on tile, and interaction within each year and applied Tukey's pairwise

143 contrasts to assess within-year differences in recruit count between groups using the 'emmeans'

144 package (Lenth, 2021).

145 The majority (99.9\%) of recruits identified to family level in the corallite scans were in

146 the families Siderastreidae, Poritidae, Agariciidae, and Faviidae (membership in Faviidae as

147 assigned in Budd and Stolarski 2011). For these identified recruits, we used a negative binomial

148 GLM with a log link to assess the effects of coral family and tile surface (top, side, and bottom)

149 on recruit count from corallite scans. We also included year and site as fixed factors, to account

150 for temporal and spatial autocorrelation, and included area of tile surfaces as an offset variable.

151 Because site depth potentially drives the tile surface of scleractinian recruitment (Rogers et al.,

152 1984), we included depth as a covariate. The model allowed for interactions between coral

153 family, location on tile, and depth. We tested for significance of fixed effects with Type II

154 analysis of deviance and evaluated significant differences in settlement orientation within

155 families using Tukey's pairwise contrast. To test the significance of individual scleractinian

156 families' relationships between recruitment location on tile and depth, we used simple linear

157 regressions with site-wide proportions of each family on tops, bottoms, and sides of tiles as

158 response variables and depth as the explanatory variable. For regressions revealing significant

159 relationships, we calculated Pearson's product moment correlation coefficients.

160 Finally, for octocorals, we used a generalized linear model (quasipoisson family with a

$161 \log$ link) to regress total live recruit count against the factors of tile surface (top and bottom) and 
162 year, with depth as a covariate, allowing for interaction between tile surface and depth. After

163 assessing model assumptions visually, we tested for significance of fixed effects with Type II

164 analysis of deviance and evaluated significant differences in tile surface within each year using

165 Tukey's pairwise contrast. For all analyses, extreme values were trimmed from figures where

166 necessary for readability (as reported in figure legends) but were incorporated in statistical

167 analyses.

168 Results

169 Over three years, we deployed 2880 tile pairs and retrieved 2778 (96\% retrieval). Most of the

170 unretrieved tile pairs (93 of 102) were lost during the 2017-2018 deployment, when Hurricane

171 Irma made landfall in the Florida Keys. In all three years, significantly more scleractinians were

172 found in corallite than live scans on both the top and bottom tile surfaces (ANOVA $p<0.001$;

173 Fig. 3, Table 1), with a significant interaction between scan method and tile surface (ANOVA

$174 \mathrm{p}=0.008$ ). Overall, we found $379 \%$ more recruits in corallite than live scans (excluding those

175 found on tile sides, which were not scanned live).

176 Corallite scans found significantly higher numbers of scleractinian recruits on top

177 compared to bottom surfaces of tiles in each year (Tukey $p<0.001$ for 2016 and 2018; Tukey

$178 \mathrm{p}=0.001$ for 2017; Fig. 3, Table 1). When the data were pooled across all three years, our recruit

179 community was dominated by siderastreids, which settled in vastly higher numbers on tile tops,

180 followed by sides and bottoms (Tukey's $p<0.001$ for top-side and top-bottom contrasts; Fig. 4,

181 Table 2). Poritids were our second most common group, and they also showed a strong

182 preference for tile tops (Tukey's, top-bottom $\mathrm{p}<0.001$ ), followed by bottoms (Tukey's, side-

183 bottom $\mathrm{p}<0.001$ ). Agariciids preferentially settled on tile bottoms (Tukey's, bottom-side

$184 \mathrm{p}<0.001$, bottom-top $\mathrm{p}<0001$ ), but were our third most common family. Faviid settlement was 
185 low overall, with significantly more recruits found on tops and bottoms than tile sides each

186 (Tukey's, side-top $\mathrm{p}=0.007$, side-bottom $\mathrm{p}=0.002$ ).

187 Tile surface interacted with site depth and coral family (ANOVA $\mathrm{p}<0.001$, Table 2),

188 though depth alone did not have a significant effect on the number of recruits. Simple linear

189 regression determined that the proportion of siderastreid recruits on the tops of tiles increased

190 with increasing depth ( $\mathrm{p}=0.042, \mathrm{r}=0.24$; Fig. 5). Additionally, the proportion of faviids $(\mathrm{p}=0.028$,

$191 \mathrm{r}=0.33)$ and poritids $(\mathrm{p}<0.001, \mathrm{r}=0.37)$ that settled on the sides of tiles increased with increasing

192 site depth (Fig. 5).

193 Live octocoral recruit counts varied significantly by year, and tile surface (ANOVA, year

$194 \mathrm{p}<0.001$, tile surface $\mathrm{p}=0.003$; Fig. 6 , Table 3 ), with site-level density ranging from $0 \mathrm{~m}^{-2}$ to

$195182.6 \mathrm{~m}^{-2}$. In 2016, mean site-level octocoral recruit density was $3.8 \pm 1.8 \mathrm{~m}^{-2}$, but mean densities

196 rose to $16.6 \pm 6.3 \mathrm{~m}^{-2}$ in 2017 and $8.1 \pm 4.0 \mathrm{~m}^{-2}$ in 2018 . Overall, $67 \%$ of octocorals were on tile

197 tops, though the pairwise within-year difference between top and bottom surfaces was only

198 significant in 2018 (Tukey's, 2018 top-bottom contrast $\mathrm{p}<0.001$ ). While overall octocoral

199 recruitment did not vary with site depth, the interaction between depth and location on tile was

200 significant $(\mathrm{p}<0.001)$.

\section{Discussion}

202 In our three year study of coral recruitment to the Florida Reef Tract, we counted scleractinian

203 recruits in both live and corallite scans and found significantly more recruits in corallite scans

204 overall. While others have acknowledged that removing tissue of corals and fouling organisms

205 may result in a higher recruit count (Arnold \& Steneck, 2011), this difference has rarely been

206 quantified. We attribute the difference between corallite and live scan counts to recruits that were

207 overgrown, smothered by sediment, otherwise dead, and/or very small $(<0.5 \mathrm{~mm})$ and likely 
208 obscured during live scans. The significant interaction between scan method and tile surface may

209 reflect the difficulty in locating small recruits during live scans on heavily sedimented top

210 surfaces of tiles. This large discrepancy in numbers on the same tiles indicates that scleractinian

211 recruitment rates should not be directly compared between studies only performing live scans

212 and those quantifying recruitment on tiles that have been post-processed to remove fouling

213 material. These results also suggest that for studies focusing on overall scleractinian recruitment

214 without concern for the effect of post-settlement survivorship, soaking tiles in sodium

215 hypochlorite provides a more accurate estimate than live scans.

216 Contrary to most assessments of scleractinian settlement orientation in shallow water, we

217 found the majority of recruit corallites on the top surfaces of our settlement tiles in every year of

218 our study (Fig. 3). Scleractinians have been reported to settle predominantly on bottom surfaces

219 of tiles because that side of the tile mimics the natural cryptic microhabitats preferred for

220 settlement (Green \& Edmunds, 2011; Humanes \& Bastidas, 2015). Further, studies that include

221 sites deeper than $10 \mathrm{~m}$ tend to reveal a shift in settlement orientation from tile bottoms and sides

222 to tops with increasing depth (Rogers et al., 1984; Babcock \& Mundy, 1996). While our study

223 identified some shifts in the proportion of recruits that settled to tile top (siderastreids) and side

224 surfaces (poritids and faviids) with increasing site depth, these shifts were modest and not

225 consistent across the coral families (Fig. 5). Because increasing site depth does not explain the

226 overall majority of settlement to tile tops observed in our study, we propose that including

227 rugosity on tile tops in this study may have enhanced recruitment to that surface (Nozawa,

228 Tanaka, \& Reimer, 2011; Edmunds, Nozawa, \& Villanueva, 2014). Thus, biases are introduced

229 in recruitment studies when top and bottom tile surfaces differ in rugosity and/or quantification is

230 limited to tile bottoms. 
231 Regardless of site depth, the proportion of settlement to top and bottom surfaces varied

232 by scleractinian family. Siderastreids and poritids settled predominantly on tile tops, while

233 agariciids settled predominantly on tile bottoms. Therefore, biases introduced by differences in

234 tile rugosity or by only scanning tile bottoms may over- or underestimate the relative

235 contributions of scleractinian families to overall recruitment. Agariciids usually settle cryptically

236 (Morse et al., 1988) and often dominate Caribbean recruit communities (Rogers et al., 1984;

237 Arnold and Steneck, 2011). Had we only quantified recruits on tile bottoms, we would have

238 concluded that agariciids were the dominant member of our recruit community, consistent with

239 prior studies. We also would have significantly underestimated recruitment by siderastreids,

240 reducing it to a level comparable to that of faviids. Thus, our decision to scan tile tops in addition

241 to bottoms has profound implications for any ecological conclusions on the relative recruitment

242 of these coral families in our study region.

243 As with scleractinians, we found more octocoral recruits on tile tops $(67 \%$ of the three

244 year total) compared to bottoms; although this difference was only significant in 2018 , it

245 emphasizes the importance of scanning all tile surfaces. This majority of recruits on the top

246 surfaces is unlikely to be explained by a survivorship advantage there, as studies which have

247 deployed lab-reared recruits in situ have found low survivorship on tile tops (Lasker, Kim, \&

248 Coffroth,1998; Evans, Coffroth, \& Lasker, 2013). Without the ability to measure overall

249 recruitment (i.e., conducting a corallite scan) as can be done for scleractinians, counts of living

250 octocoral recruits on tiles, regardless of surface, include some level of post-settlement mortality.

251 The abundance per survey area of octocoral recruits in situ is highly variable, making the

252 assessment of post-settlement mortality on octocoral recruit densities difficult (Lasker \& Porto-

253 Hannes, 2021), compounded with the difficulty of seeing very small recruits. However, tiles can 
254 be examined under a microscope, likely allowing for smaller recruits to be counted than through

255 in situ surveys. The densities of live octocoral recruits in our study were on par or higher than

256 those that have been found during in situ surveys (Privitera-Johnson, Lenz, \& Edmunds, 2015;

257 Lasker \& Porto-Hannes, 2021), indicating the viability of settlement tiles for the study of

258 octocoral recruitment. While assessments of recruit survivorship were beyond the scope of our

259 study, researchers may be able to use tiles to more clearly assess the effects of post-settlement

260 mortality on octocoral recruitment than can be done during in situ surveys. For example, tiles can

261 be collected, scanned for even very small living recruits under a microscope, and redeployed for

262 repeated live recruit scans, as has been done for scleractinians (Arnold, Steneck, \& Mumby

263 2010; Arnold \& Steneck, 2011)

\section{Conclusions}

265 Our three-year, region-wide recruitment study provided an opportunity to evaluate

266 methodological considerations that may confound efforts to compare coral recruitment rates

267 between studies that used different methods. First, we found higher densities of scleractinian

268 recruits in corallite than live scans, indicating that while live scans can have useful applications

269 such as quantifying post-settlement survival or allowing for molecular identification of recruits,

270 they are likely to underestimate overall scleractinian recruitment rates when directly compared to

271 studies that examine tiles treated with sodium hypochlorite. We recommend that, for

272 comparisons of global scleractinian recruitment, tiles should be scanned after being processed for

273 the removal of sediment and benthic organisms that could obscure the detection of small recruits.

274 Second, we found more scleractinian recruits on tile tops than bottoms, indicating that rugosity

275 should be uniform on both surfaces, to ensure that differences in recruitment rates to these

276 surfaces are due to ecological and not methodological factors. Further, scanning all surfaces of 
277 the tiles will avoid mischaracterizing the relative contribution of identified scleractinian recruit

278 taxa to the overall recruitment rate. Finally, we propose that tiles also can be used to enumerate

279 living octocoral recruits, and studies that do so should abide by the same recommendations for

280 uniform tile rugosity and scanning both tops and bottoms of the tiles.

281

\section{Acknowledgements}

283 We thank the many Florida Fish and Wildlife Research Institute staff and Nova Southeastern

284 University graduate students who deployed, retrieved, and live-scanned settlement tiles.

\section{Conflict of Interest Statement}

286 On behalf of all authors, the corresponding author states that there is no conflict of interest.

\section{References}

288 Arnold SN, Steneck RS, Mumby PJ (2010) Running the gauntlet: inhibitory effects of algal turfs 289 on the processes of coral recruitment. Mar Ecol Prog Ser 414:91-105

290 Arnold SN, Steneck RS (2011) Settling into an increasingly hostile world: the rapidly closing

291 "recruitment window" for corals PLoS ONE 6(12):

292 e28681.doi:10.1371/journal.pone.0028681

293 Adjeroud M, Penin L, Carroll A (2007) Spatio-temporal heterogeneity in coral recruitment 294 around Moorea, French Polynesia: Implications for population maintenance. J Exp Mar

$295 \quad$ Biol Ecol 341:204-218

296 Babcock R, Mundy C (1996) Coral recruitment: Consequences of settlement choice for early 297 growth and survivorship in two scleractinians. J Exp Mar Biol Ecol 206:179-201 
298 Budd AF, Foster Jr. CT, Dawnson JP, Johnson KG (2001) The Neogene marine biota of tropical 299 America ("NMITA") database: accounting for biodiversity in paleontology. J Paleont $300 \quad 75(3): 743-751$

301 Budd AF, Stolarski J (2011) Corallite wall and septal microstructure in scleractinian reef corals: 302 Comparison of molecular clades within the family Faviidae. J Morphol 272:66-88

303 Burt J, Bartholomew A, Bauman A, Saif A, Sale P (2009) Coral recruitment and early benthic 304 community development on several materials used in the construction of artificial reefs 305 and breakwaters. J Exp Mar Biol Ecol 373:72-78

306 Burt JA, Bauman AG (2020) Suppressed coral settlement following mass bleaching in the 307 southern Persian/Arabian Gulf. Aquat Ecosyst Health Manag 23:166-174

308 Chong-Seng K, Graham N, Pratchett M (2014) Bottlenecks to coral recovery in the Seychelles. 309 Coral Reefs 33:449-461

310 Davidson J, Thompson A, Logan M, Schaffelke B (2019) High spatio-temporal variability in Acroporidae settlement to inshore reefs of the Great Barrier Reef. PLoS ONE 14:e209771

Doropoulos C, Roff G, Zupan M, Nestor V, Isechal AL, Mumby PJ (2014) Reef-scale failure of coral settlement following typhoon disturbance and macroalgal bloom in Palau, Western

316 Edmunds PJ (2017) Unusually high coral recruitment during the 2016 El Niño in Mo'orea, French Polynesia. PLoS ONE 12:e0185167

318 Edmunds P, Gates R, Gleason D (2001) The biology of larvae from the reef coral Porites astreoides, and their response to temperature disturbances. Marine Biology 139:981-989 
320 Edmunds PJ, Lasker HR (2016) Cryptic regime shift in benthic community structure on shallow

321 reefs in St. John, US Virgin Islands. Mar Ecol Prog Ser 559:1-12

322 Edmunds PJ, Nozawa Y, Villanueva RD (2014) Refuges modulate coral recruitment in the

323 Caribbean and the Pacific. J Exp Mar Biol Ecol 454:78-84

324 Evans M, Coffroth M, Lasker H (2013) Effects of predator exclusion on recruit survivorship in 325 an octocoral (Briareum asbestinum) and a scleractinian coral (Porites astreoides). Coral

$326 \quad$ Reefs 32:597-601

327 Evans RD, Wilson SK, Fisher R, Ryan NM, Babcock R, Blakeway D, Bond T, Dorji P, Dufois F,

328 Fearns P, Lowe RJ, Stoddart J, Thomson DP (2020) Early recovery dynamics of turbid

329 coral reefs after recurring bleaching events. J Environ Manage 268:110666

330 Fox J, Weisberg S (2019) An R Companion to Applied Regression, Third edition. Sage,

331 ThousandOaks CA. https://socialsciences.mcmaster.ca/jfox/Books/Companion/

332 Gouezo M, Olsudong D, Fabricius K, Harrison P, Golbuu Y, Doropoulos C (2020) Relative roles

333 of biological and physical processes influencing coral recruitment during the lag phase of

334 reef community recovery. Sci Rep 10:1-12

335 Green DH, Edmunds PJ (2011) Spatio-temporal variability of coral recruitment on shallow reefs in St. John, US Virgin Islands. J Exp Mar Biol Ecol 397:220-229

337 Guerrini G, Yerushalmy M, Shefy D, Shashar N, Rinkevich B (2020) Apparent recruitment

338 failure for the vast majority of coral species at Eilat, Red Sea. Coral Reefs 39:1715-1726

339 Harriott VJ, Fisk DA (1987) A comparison of settlement plate types for experiments on the

340 recruitment of scleractinian corals. Mar Ecol Prog Ser 37:201-208

341 Humanes A, Bastidas C (2015) In situ settlement rates and early survivorship of hard corals: a good year for a Caribbean reef. Mar Ecol Prog Ser 539:139-151 
343 Humblet, M., Hongo C, Sugihara K (2015) An identification guide to some major Quaternary

344 fossil reef-building coral genera (Acropora, Isopora, Montipora, and Porites). Isl. Arc.

$345 \quad 24: 16-30$.

346 Jouval F, Letreille AC, Bureau S, Adjeroud M, Penin L (2019) Multiscale variability in coral

347 recruitment in the Mascarene Islands: From centimetric to geographical scale. PLoS ONE

$348 \quad$ 14(3):e0214163

349 Lal R, Kininmonth S, N'Yeurt AD, Riley RH, Rico C (2018) The effects of a stressed inshore

350 urban reef on coral recruitment in Suva Harbour, Fiji. Ecol Evol 8:11842-11856

351 Lasker HR (2013) Recruitment and resilience of a harvested Caribbean octocoral. PLoS ONE

$352 \quad 8: e 74587$

353 Lasker HR, Kim K, Coffroth MA (1998) Production, settlement, and survival of plexaurid

354 gorgonian recruits. Mar Ecol Prog Ser 162:111-123

355 Lasker HR, Martínez-Quintana Á, Bramanti L, Edmunds P (2020) Resilience of octocoral forests

356 to catastrophic storms. Sci Rep 10:1-8

357 Lasker HR, Porto-Hannes I (2021) Species level identification of Antillogorgia spp. recruits

358 identifies multiple pathways of octocoral success on Caribbean reefs. Coral Reefs 40:41-

$359 \quad 51$

360 Lenth RV (2021). Emmeans: estimated marginal means, aka least-squares means.

361 https://cran.r-project.org/web/packages/emmeans/index.html

362 Morse DE, Hooker N, Morse ANC, Jensen RA (1988). Control of larval metamorphosis and

363 recruitment in sympatric agariciid corals. J Exp Mar Biol Ecol 116:193-217

364 Mundy C (2000) An appraisal of methods used in coral recruitment studies. Coral Reefs 19:124$365 \quad 131$ 
366 Nozawa Y (2008) Micro-crevice structure enhances coral spat survivorship. J Exp Mar Biol Ecol $367 \quad 367: 127-130$

368 Nozawa Y, Tanaka K, Reimer JD (2011) Reconsideration of the surface structure of settlement 369 plates used in coral recruitment studies. Zool Stud 50:53-60

370 O'Cain ED, Frischer ME, Harrison JS, Walters TL, Thompson ME, Fogarty ND, Ruzicka R, 371 Gleason DF (2019) Identification of newly settled Caribbean coral recruits by ITS372 targeted single-step nested multiplex PCR. Coral Reefs 38:79-92

373 Privitera-Johnson K, Lenz EA, Edmunds PJ (2015) Density-associated recruitment in octocoral communities in St. John, US Virgin Islands. Journal of Experimental Marine Biology and Ecology 473:103109 DOI 10.1016/j.jembe.2015.08.006.

R Core Team (2020) R: A language and environment for statistical computing. R Foundation for 377 Statistical Computing, Vienna Austria. https://www.R-project.org/

Randall CJ, Giuliano C, Heyward AJ and Negri AP (2021) Enhancing Coral Survival on Deployment Devices With Microrefugia. Front. Mar. Sci. 8:662263. doi: 10.3389/fmars.2021.662263

Rogers CS, Fitz HC, Gilnack M, Beets J, Hardin J (1984) Scleractinian coral recruitment patterns at Salt River submarine canyon, St. Croix, U.S. Virgin Islands. Coral Reefs 3:69-76 Macaulay KA, Bartlett LA, Meyers MK, Colee J (2013) Temporal changes in benthic assemblages on Florida Keys reefs 11 years after the 1997/1998 El Niño. Mar Ecol Prog Ser 489:125-141

Smith, FGW (1971) Atlantic Reef Corals. University of Miami Press, Coral Gables.

van Woesik R, Scott IV WJ, Aronson RB (2014) Lost opportunities: coral recruitment does not 
390 Venables WN, Ripley BD (2002) Modern Applied Statistics with S, Fourth edition. Springer,

391 New York. ISBN 0-387-95457-0, https://www.stats.ox.ac.uk/pub/MASS4/

\section{Figure legends}

393 Figure 1. Map of Florida Reef Tract study sites. Point color is scaled to depth in meters. Sites

394 spanned four regions of the reef tract: Southeast Florida and the Upper, Middle, and Lower Keys, 395 and are labeled with numbers corresponding to Table S2. Map tiles by Stamen Design, under CC 396 BY 3.0. Data by OpenStreetMap, under ODbL.

397 Figure 2. Settlement tiles before, during and after deployment. Terracotta tiles were

398 configured in pairs, grooved sides facing outward, yielding consistent rugosity on the top and

399 bottom surfaces of the pair. Tiles were deployed by installing a green plastic drywall anchor into

400 a hole drilled into the substratum; stainless steel lag screws were used to fasten the tile pairs into

401 the anchor (A). A tile pair deployed to the reef (B) and transport racks after retrieval of tiles,

402 before surfacing (C). Tiles were submerged in trays filled with seawater for scans of living

403 recruits (D,F), then soaked in sodium hypochlorite and scanned for corallites (E,G). Images D

404 and E depict the same individual from the family Siderastreidae before and after tissue removal.

405 Images F and G depict the same individual from the family Poritidae before and after tissue

406 removal. Scale bars represent $1 \mathrm{~mm}$. Photo credits: (A) Rob Ruzicka, (B) Lindsay Huebner, (C)

407 Lauren Stefaniak, (D-G) Leah Harper.

408 Figure 3. Density of scleractinian recruits on top and bottom tile surfaces by scan method 409 (live and corallite) across $\mathbf{N}=\mathbf{3 0}$ Florida Reef Tract sites for each of three years of tile

410 deployment. Boxplots show mean density of recruits at each study site, and display the median

411 (horizontal line), the first and third quartiles (interquartile range [IQR]), $1.5 \times \mathrm{IQR}$ (whiskers), 
412 and outliers (black dots). Two outliers with density values greater than $1500 \mathrm{~m}^{-2}$ were trimmed

413 from the plot for readability $\left(2164 \mathrm{~m}^{-2}, 4128 \mathrm{~m}^{-2}\right.$; both from top surface, corallite scan, 2018$)$.

414 Letters denote significant pairwise difference of recruit count between top and bottom tile

415 surfaces, as well as live and corallite scans of each tile surface, within each year (Tukey's

$416 \mathrm{p}<0.05)$.

417 Figure 4. Density of scleractinian recruits found on tile surfaces during corallite scans

418 across $\mathbf{N}=\mathbf{3 0}$ Florida Reef Tract sites and three years of deployments. Boxplots show mean

419 density of recruits at each study site; $\mathrm{N}=90$ site-years surveyed. Boxes display the median

420 (horizontal line), the first and third quartiles (interquartile range [IQR]), $1.5 \times$ IQR (whiskers),

421 and outliers (black dots). Five outliers with density values greater than $100 \mathrm{~m}^{-2}$ were trimmed

422 from the plot for readability $\left(198 \mathrm{~m}^{-2}, 215 \mathrm{~m}^{-2}, 295 \mathrm{~m}^{-2}, 442 \mathrm{~m}^{-2}, 723 \mathrm{~m}^{-2}\right.$; all from top surface,

423 Siderastreidae). Letters denote significant differences of recruit count within scleractinian family

424 (Tukey's p<0.05).

425 Figure 5. Relationships between site depth in meters (x-axes) and proportion of corallites

426 found on each tile surface (y-axes) per scleractinian coral family. Significant linear

427 relationships are denoted with asterisks (* denotes $\mathrm{p}<0.01$; *** denotes $\mathrm{p}<0.0001)$ and the

428 Pearson product-moment correlation coefficient is shown for significant relationships.

429 Figure 6. Density of octocoral recruits found on top and bottom tile surfaces during live 430 scans across $\mathbf{N}=\mathbf{3 0}$ Florida Reef Tract sites for each of three years of deployment. Boxplots

431 show the mean density of recruits at each study site within each year. Boxes display the median

432 (horizontal line), the first and third quartiles (interquartile range [IQR]), $1.5 \times$ IQR (whiskers),

433 and outliers (black dots). Two outliers with density values greater than $200 \mathrm{~m}^{-2}$ were trimmed 
434 from the plot for readability $\left(240 \mathrm{~m}^{-2}\right.$; top surface 2018 , and $340 \mathrm{~m}^{-2}$; top surface 2017$)$. Asterisks

435 denote significant pairwise differences of recruit count within year $(* * *$ denotes $\mathrm{p}<0.001)$.

436 Table legends

437 Table 1. Type II Analysis of Deviance of a negative binomial generalized linear model 438 regressing the number of scleractinian recruits found on the top and bottom surfaces of

439 tiles (location) in live and corallite scans (method). Site and year are fixed factors. The chi-

440 square value (Chisq), degrees of freedom (df), and p-value (Pr[ $>$ Chisq]) are shown.

441 Table 2. Type II Analysis of Deviance of a negative binomial generalized linear model

442 regressing the number of scleractinian recruits against family, tile surface, and depth. Year

443 is a fixed factor. The chi-square value (Chisq), degrees of freedom (df), and p-value (Pr[ $>$ Chisq])

444 are shown.

445 Table 3. Type II Analysis of Deviance of a quasipoisson generalized linear model regressing

446 the number of octocoral recruits against tile surface and depth. Year is a fixed covariate. The

447 chi-square value (Chisq), degrees of freedom (df), and p-value (Pr[ $>$ Chisq]) are shown. 


\section{Figure 1}

Map of Florida Reef Tract study sites.

Point color is scaled to depth in meters. Sites spanned four regions of the reef tract:

Southeast Florida and the Upper, Middle, and Lower Keys, and are labeled with numbers corresponding to Table S2. Map tiles by Stamen Design, under CC BY 3.0. Data by OpenStreetMap, under ODbL.

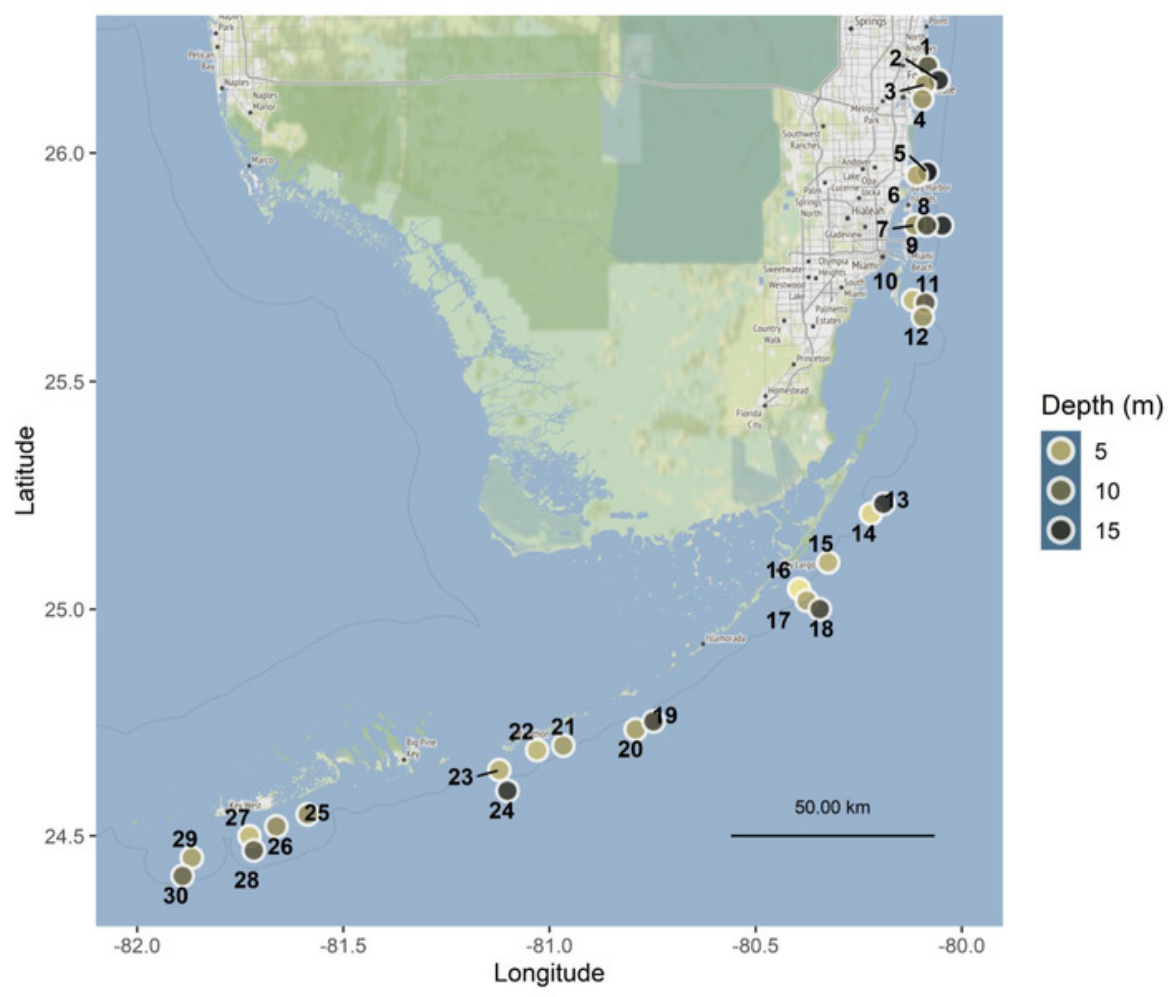




\section{Figure 2}

Settlement tiles before, during and after deployment.

Terracotta tiles were configured in pairs, grooved sides facing outward, yielding consistent rugosity on the top and bottom surfaces of the pair. Tiles were deployed by installing a green plastic drywall anchor into a hole drilled into the substratum; stainless steel lag screws were used to fasten the tile pairs into the anchor (A). A tile pair deployed to the reef (B) and transport racks after retrieval of tiles, before surfacing (C). Tiles were submerged in trays filled with seawater for scans of living recruits $(D, F)$, then soaked in sodium hypochlorite and scanned for corallites $(E, G)$. Images $D$ and $E$ depict the same individual from the family Siderastreidae before and after tissue removal. Images $F$ and $G$ depict the same individual from the family Poritidae before and after tissue removal. Scale bars represent $1 \mathrm{~mm}$. Photo credits: (A) Rob Ruzicka, (B) Lindsay Huebner, (C) Lauren Stefaniak, (D-G) Leah Harper.
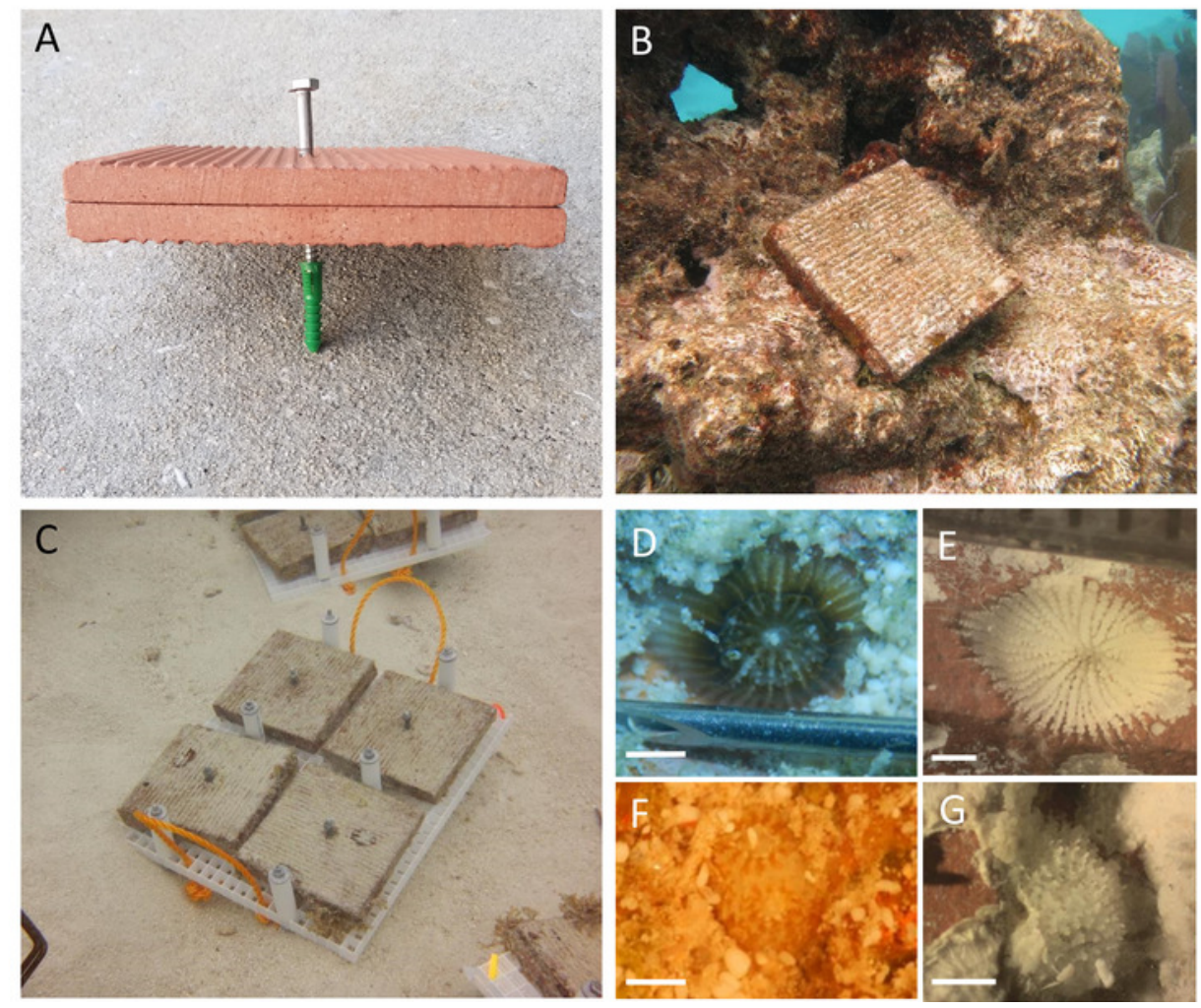


\section{Figure 3}

Density of scleractinian recruits on top and bottom tile surfaces by scan method (live and corallite) across $\mathrm{N}=30$ Florida Reef Tract sites for each of three years of tile deployment.

Boxplots show mean density of recruits at each study site, and display the median (horizontal line), the first and third quartiles (interquartile range [IQR]), $1.5 \times I Q R$ (whiskers), and outliers (black dots). Two outliers with density values greater than $1500 \mathrm{~m}^{-2}$ were trimmed from the plot for readability $\left(2164 \mathrm{~m}^{-2}, 4128 \mathrm{~m}^{-2}\right.$; both from top surface, corallite scan, 2018). Letters denote significant pairwise difference of recruit count between top and bottom tile surfaces, as well as live and corallite scans of each tile surface, within each year (Tukey's $p<0.05$ ).

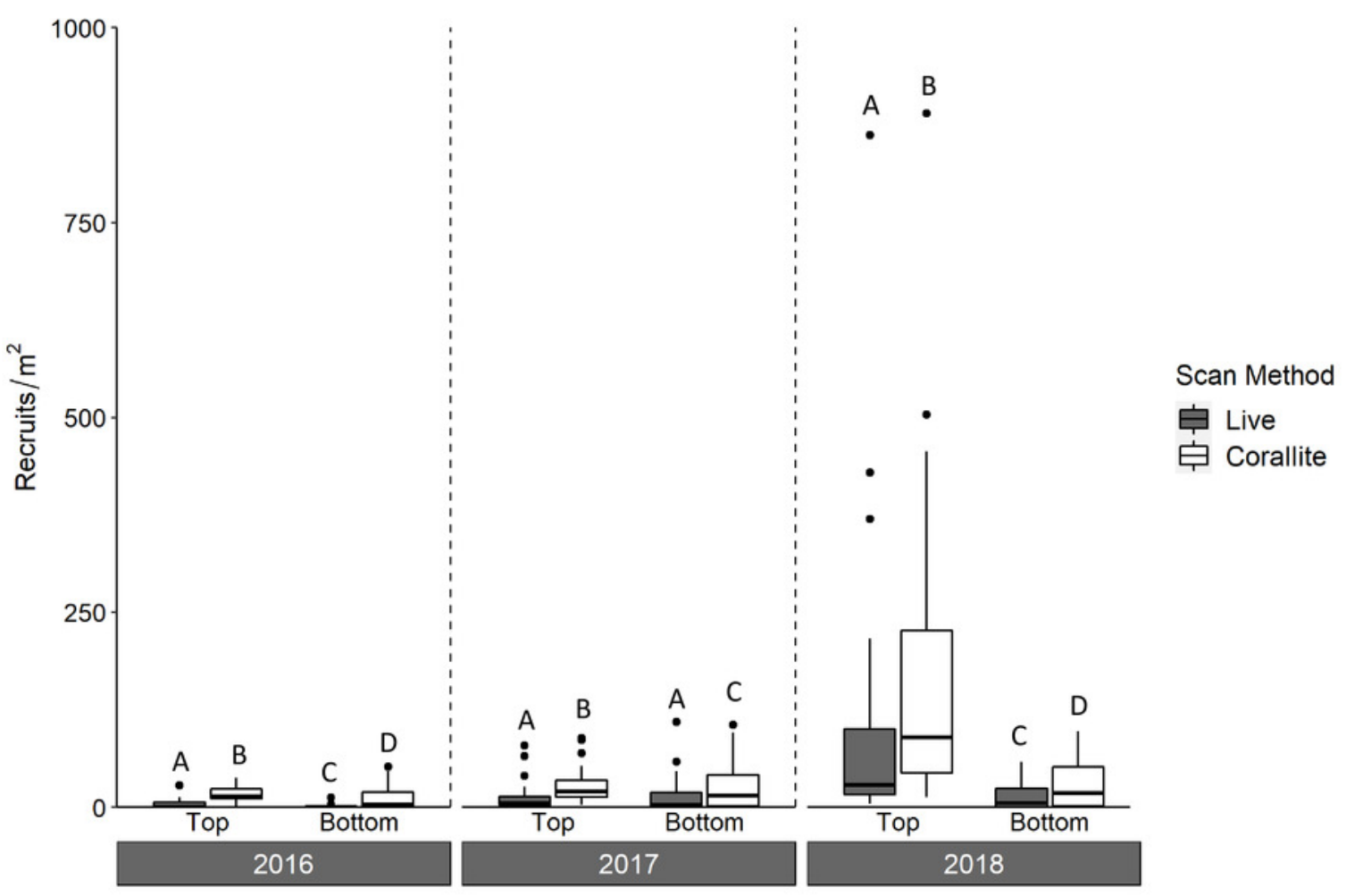




\section{Figure 4}

Density of scleractinian recruits found on tile surfaces during corallite scans across $\mathrm{N}=$ 30 Florida Reef Tract sites and three years of deployments.

Boxplots show mean density of recruits at each study site; $\mathrm{N}=90$ site-years surveyed. Boxes display the median (horizontal line), the first and third quartiles (interquartile range [IQR]), $1.5 \times$ IQR (whiskers), and outliers (black dots). Five outliers with density values greater than $100 \mathrm{~m}^{-2}$ were trimmed from the plot for readability $\left(198 \mathrm{~m}^{-2}, 215 \mathrm{~m}^{-2}, 295 \mathrm{~m}^{-2}, 442 \mathrm{~m}^{-2}, 723 \mathrm{~m}^{-2}\right.$; all from top surface, Siderastreidae). Letters denote significant differences of recruit count within scleractinian family (Tukey's $p<0.05$ ).

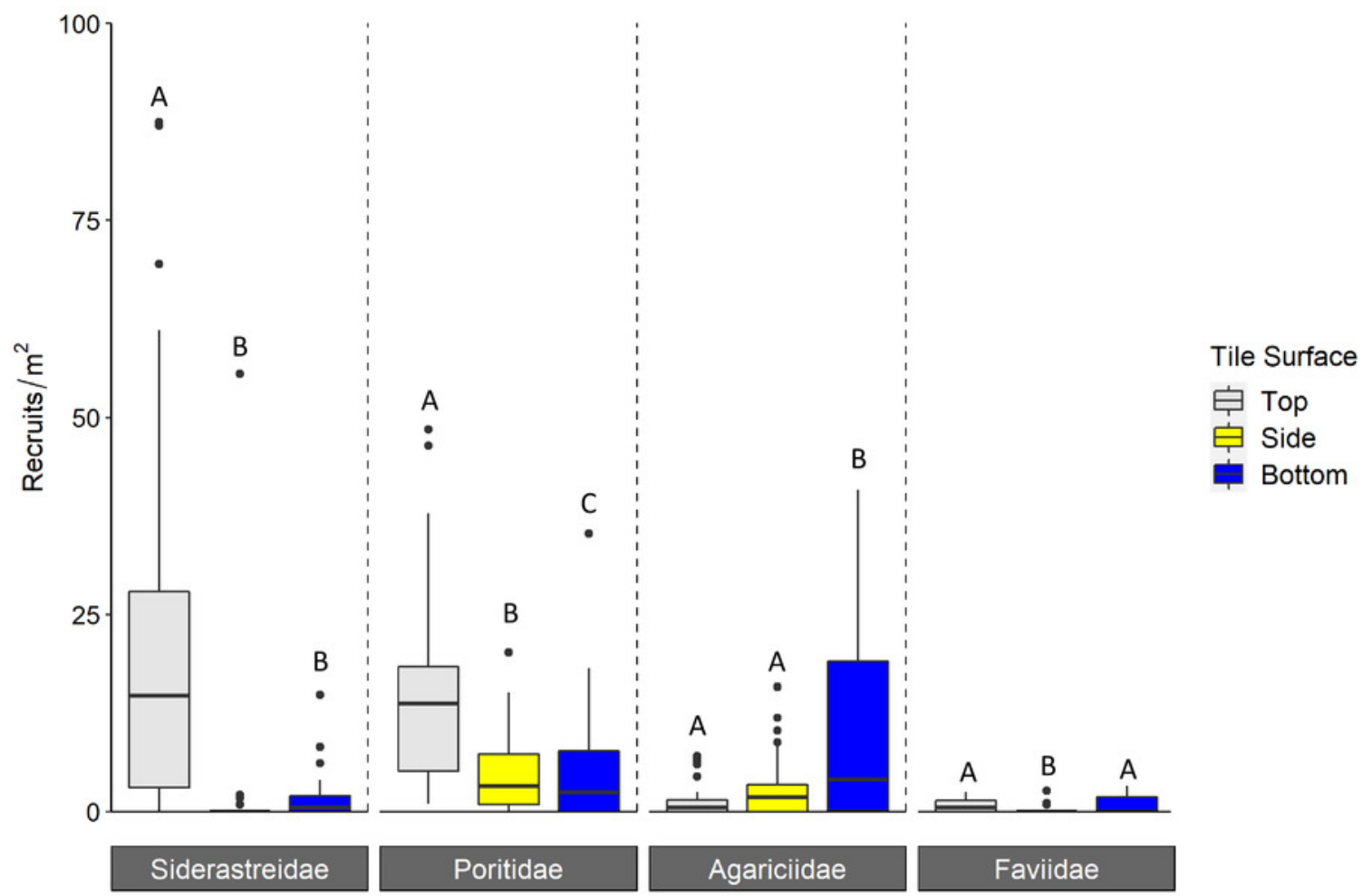


Figure 5

Relationships between site depth in meters (x-axes) and proportion of corallites found on each tile surface ( $y$-axes) per scleractinian coral family.

Significant linear relationships are denoted with asterisks $(*$ denotes $p<0.01 ; * * *$ denotes $p<0.0001)$ and the Pearson product-moment correlation coefficient is shown for significant relationships.
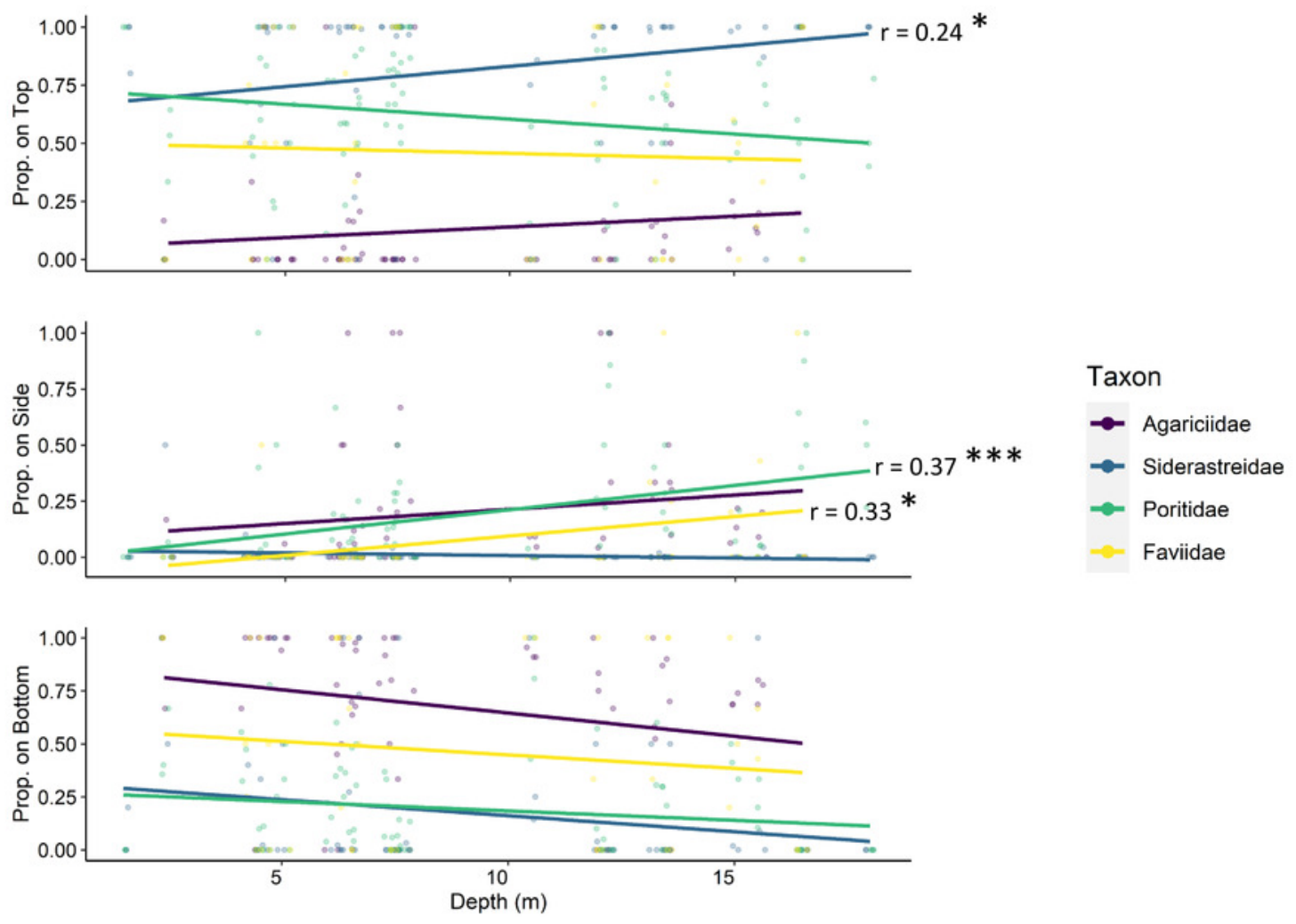


\section{Figure 6}

Density of octocoral recruits found on top and bottom tile surfaces during live scans across $\mathrm{N}=30$ Florida Reef Tract sites for each of three years of deployment.

Boxplots show the mean density of recruits at each study site within each year. Boxes display the median (horizontal line), the first and third quartiles (interquartile range [IQR]), $1.5 \times$ IQR (whiskers), and outliers (black dots). Two outliers with density values greater than $200 \mathrm{~m}^{-2}$ were trimmed from the plot for readability $\left(240 \mathrm{~m}^{-2}\right.$; top surface 2018 , and $340 \mathrm{~m}^{-2}$; top surface 2017). Asterisks denote significant pairwise differences of recruit count within year (*** denotes $p<0.001)$.

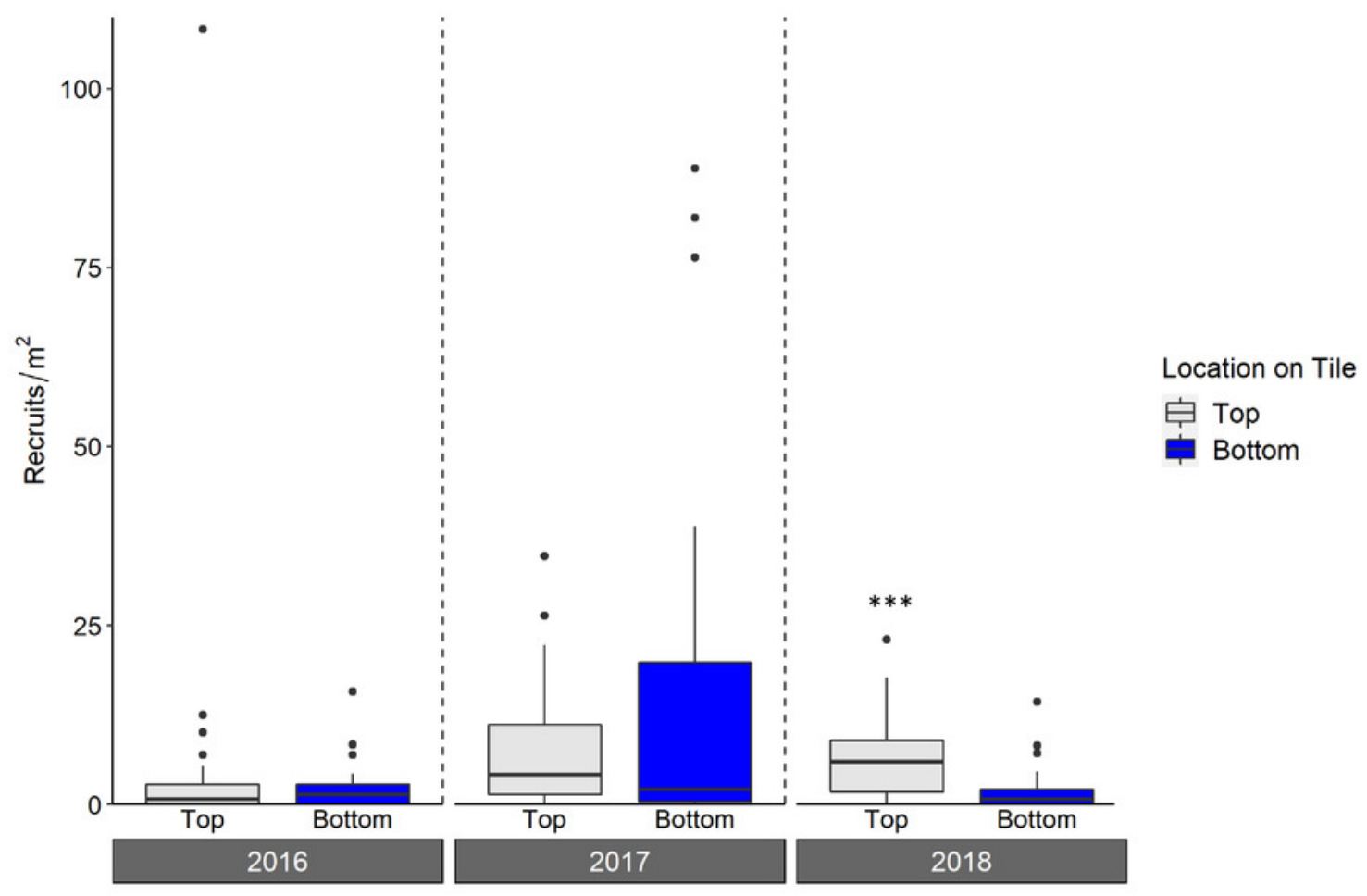




\section{Table $\mathbf{1}$ (on next page)}

Type II Analysis of Deviance of a negative binomial generalized linear model regressing the number of scleractinian recruits found on the top and bottom surfaces of tiles (location) in live and corallite scans (method).

Site and year are fixed factors. The chi-square value (Chisq), degrees of freedom (df), and pvalue (Pr[>Chisq]) are shown. 
1 Table 1. Type II Analysis of Deviance of a negative binomial generalized linear model 2 regressing the number of scleractinian recruits found on the top and bottom surfaces of 3 tiles (location) in live and corallite scans (method). Site and year are fixed factors. The chi4 square value (Chisq), degrees of freedom (df), and p-value (Pr[>Chisq]) are shown.

5

\begin{tabular}{|lrrr|}
\hline & \multicolumn{1}{c}{ Chisq } & Df & $\operatorname{Pr}(>$ Chisq $)$ \\
\hline Location on Tile & 440.98 & 1 & $<0.001$ \\
Method & 563.02 & 1 & $<0.001$ \\
Year & 1287.02 & 2 & $<0.001$ \\
Site & 1111.11 & 29 & $<0.001$ \\
Interaction of & 7.02 & 1 & 0.008 \\
Location \& Method & & & \\
\hline
\end{tabular}

6

7 


\section{Table 2 (on next page)}

Type II Analysis of Deviance of a negative binomial generalized linear model regressing the number of scleractinian recruits against family, tile surface, and depth.

Year is a fixed factor. The chi-square value (Chisq), degrees of freedom (df), and p-value $(\operatorname{Pr}[>$ Chisq $])$ are shown. 
1 Table 2. Type II Analysis of Deviance of a negative binomial generalized linear model

2 regressing the number of scleractinian recruits against family, tile surface, and depth. Year

3 is a fixed factor. The chi-square value (Chisq), degrees of freedom (df), and p-value (Pr[ $>C h i s q])$

4 are shown.

\begin{tabular}{|c|c|c|c|c|}
\hline Factor & Chisq & Df & & $\operatorname{Pr}(>$ Chisq $)$ \\
\hline Taxon & 993.87 & & 3 & $<0.001$ \\
\hline Tile Surface & 1001.04 & & 2 & $<0.001$ \\
\hline Depth & 2.98 & & 1 & 0.084 \\
\hline Year & 478.82 & & 2 & $<0.001$ \\
\hline Taxon x Tile Surface & 1044.3 & & 6 & $<0.001$ \\
\hline Taxon x Depth & 56.76 & & 3 & $<0.001$ \\
\hline Tile Surface x Depth & 28.57 & & 2 & $<0.001$ \\
\hline Taxon x Tile Surface x Depth & 26.16 & & 6 & $<0.001$ \\
\hline
\end{tabular}

5 


\section{Table 3(on next page)}

Type II Analysis of Deviance of a quasipoisson generalized linear model regressing the number of octocoral recruits against tile surface and depth.

Year is a fixed covariate. The chi-square value (Chisq), degrees of freedom (df), and p-value $(\operatorname{Pr}[>$ Chisq $])$ are shown. 
1 Table 3. Type II Analysis of Deviance of a quasipoisson generalized linear model regressing 2 the number of octocoral recruits against tile surface and depth. Year is a fixed covariate. The 3 chi-square value (Chisq), degrees of freedom (df), and p-value (Pr[ $>$ Chisq]) are shown.

4

\begin{tabular}{|lrrr|}
\hline & Chisq & Df & $\operatorname{Pr}(>$ Chisq $)$ \\
\hline Location on Tile & 43.56 & 1 & $<0.001$ \\
Depth & 3.06 & 1 & 0.081 \\
Interaction of & 82.35 & 1 & $<0.001$ \\
Location \& Depth & & 2 & $<0.001$ \\
Year & 120.29 & 2 & \\
\hline
\end{tabular}

5 